\title{
CAMINHABILIDADE E ACESSIBILIDADE URBANA PARA A POPULAÇÃO IDOSA: UMA ANÁLISE EM CAMPOS DOS GOYTACAZES-RJ
}

\author{
Jefferson da Silva Carvalho'* \& Aline Couto da Costa
}

\begin{abstract}
RESUMO
CARVAlHO, J.; COSTA, A. C.; Caminhabilidade e Acessibilidade Urbana para a População Idosa: Uma análise em Campos dos Goytacazes-RJ. Perspectivas Online: Humanas \& Sociais Aplicadas, v.9, n.24, p. 14-30, 2019.

O envelhecimento da população gera uma mudança na forma com que as dinâmicas urbanas acontecem. É preciso repensar o planejamento da cidade considerando, dentre outros, a qualidade das calçadas e a grande quantidade de idosos que caminham nas ruas. Apesar da crescente preocupação sobre a qualidade urbana, o idoso não é considerado plenamente no planejamento da cidade ao que diz respeito à infraestrutura urbana em questão de acessibilidade e mobilidade, sendo necessários estudos e políticas públicas para que a sociedade, em especial a parcela idosa, tenha autonomia para se locomover nas ruas e estar inserida efetivamente na vida social da cidade. O objetivo desse

trabalho consiste em desenvolver e apresentar uma análise da qualidade da infraestrutura atual de um trecho da Av. José Alves de Azevedo em relação à caminhabilidade focada nos idosos. Para isso, foram realizadas pesquisas bibliográficas e documentais; seleção de indicadores de análise; e discussão dos dados de acordo com a legislação municipal e federal. Os resultados demonstram que os espaços públicos voltados ao idoso precisam ser remodelados. Acredita-se que esse trabalho possa contribuir par a conscientização do problema e para a adoção de medidas de acessibilidade no meio urbano em prol da qualidade de vida do idoso na cidade.
\end{abstract}

Palavras-chave: Caminhabilidade; Acessibilidade Urbana; Idosos. 


\begin{abstract}
The ageing of the population generates a change in the way urban dynamics happen. It Is necessary to rethink the planning of the city, considering, among others, the quality of the sidewalks and the large number of elderly people walking on the streets. Despite the growing concern about urban quality, the elderly is not fully considered in the planning of the city with regard to the urban infrastructure in question of accessibility and mobility, and it is necessary studies and public policies to Society, especially the elderly, has autonomy to get around the streets and be effectively inserted in the social life of the

develop and present an analysis of the quality of the current infrastructure of a pathway in relation to the Walker focused on the elderly. For this, bibliographical and documentary researches were conducted; selection of analysis indicators; and discussion of data in accordance with municipal and federal legislation. The results show that public spaces aimed at the elderly need to be remodeled. It is Believed that this work can contribute to the awareness of the problem and to the adoption of accessibility measures in the urban environment in favor of the quality of life of the elderly in the city.
\end{abstract} city. The objective of this work is to

Keywords: Walkability; Urban Accessibilitu; Elderly.

\footnotetext{
${ }^{1}$ Arquiteto e Urbanista - IFF; Aluno da Pós Graduação Lato Sensu em Arquitetura da Cidade: suas demandas e tecnologias Instituto Federal Fluminense - campus Campos Centro; Rua Doutor Siqueira, 273, Parque Don Bosco, Campos dos Goytacazes, RJ, CEP: 28030-130, Brasil.

${ }^{2}$ Doutora em Arquitetura - PROARQ/FAU/UFRJ; Professora do Instituto Federal Fluminense - campus Campos Centro; Rua Doutor Siqueira, 273, Parque Don Bosco, Campos dos Goytacazes, RJ, CEP: 28030-130, Brasil.

(*) e-mail: jeffersoncarvalho.au@gmail.com

Data de recebimento: 27/03/2019. Aceito para publicação: 30/04/2019.
} 


\section{INTRODUÇÃO}

A população brasileira está envelhecendo consideravelmente nos últimos anos e, em contrapartida, é observada a diminuição do número de crianças. De acordo com o Instituto Brasileiro de Geografia e Estatísticas (AGÊNCIA DE NOTÍCIAS IBGE, 2016), entre 2012 e 2016, a população com 60 anos de idade ou mais teve um aumento de 16,0\%, chegando a 29,6 milhões de pessoas; enquanto a quantidade de indivíduos com até nove anos de idade caiu de $14,1 \%$ para $12,9 \%$ durante o mesmo período.

Segundo o censo demográfico do IBGE de 2010 (SIDRA, 2019) apresentado pela Tabela 01, na área urbana da cidade de Campos dos Goytacazes, a população com idade igual ou superior a 60 anos somava mais de 49.000 habitantes. A tabela apresenta a quantidade da população com idade de 60 a 69 anos e com 70 anos ou mais separada por sexo no Brasil, no estado do Rio de Janeiro e na cidade de Campos dos Goytacazes. Destaca, ainda, a quantidade desse grupo na área urbana das localidades citadas. Considerando que o censo foi feito há praticamente uma década, estima-se que hoje esse número seja muito maior, devido ao envelhecimento da população brasileira constatado entre 2012 e 2016.

Tabela 01: População residente por idade, sexo e situação de domicílio (na área urbana) no ano de 2010 no Brasil, no estado do Rio de Janeiro e no município de Campos dos

Goytacazes (Fonte: Adaptado de IBGE/SIDRA, 2019)

\begin{tabular}{|c|c|c|c|c|c|c|c|}
\hline \multirow{3}{*}{ Brasil, Unidade da Federação e Municipio } & \multirow{3}{*}{ Idade } & \multicolumn{6}{|c|}{ Situação do domicilio x Sexo } \\
\hline & & \multicolumn{3}{|c|}{ Total } & \multicolumn{3}{|c|}{ Urbana } \\
\hline & & Total & Homens & Mulheres & Total & Homens & Mulheres \\
\hline \multirow{3}{*}{ Brasil } & Total & 190.755 .799 & 93.406 .990 & 97.348 .809 & 160.925 .804 & 77.710 .179 & 83.215 .625 \\
\hline & 60 a 69 anos & 11.349 .930 & 5.265 .100 & 6.084 .830 & 9.514 .960 & 4.272 .680 & 5.242 .280 \\
\hline & 70 anos ou mais & 9.240 .667 & 3.891.011 & 5.349 .656 & 7.809 .434 & 3.158 .101 & 4.651 .333 \\
\hline \multirow{3}{*}{ Rio de Janeiro } & Total & 15.989 .929 & 7.625 .679 & 8.364 .250 & 15.464 .239 & 7.354 .325 & 8.109 .914 \\
\hline & 60 a 69 anos & 1.130 .086 & 496.422 & 633.664 & 1.095 .162 & 477.572 & 617.590 \\
\hline & 70 anos ou mais & 950.522 & 361.261 & 589.261 & 924.434 & 347.983 & 576.451 \\
\hline \multirow{3}{*}{ Campos dos Goytacazes (RJ) } & Total & 463.731 & 223.259 & 240.472 & 418.725 & 200.256 & 218.469 \\
\hline & 60 a 69 anos & 30.230 & 13.426 & 16.804 & 27.126 & 11.800 & 15.326 \\
\hline & 70 anos ou mais & 24.811 & 10.168 & 14.643 & 22.409 & 8.943 & 13.466 \\
\hline
\end{tabular}

Considerando o contexto da legislação, em 2003, foi instituído o Estatuto do Idoso, ou Lei $\mathrm{n}^{\mathrm{o}} 10.741$ de $1^{\circ}$ de outubro de 2003, que regula os direitos das pessoas com 60 anos ou mais. No artigo $2^{\circ}$, é dada a seguinte declaração:

Art. 2-OO idoso goza de todos os direitos fundamentais inerentes à pessoa humana, sem prejuízo da proteção integral de que trata esta Lei, assegurando-se-lhe, por lei ou por outros meios, todas as oportunidades e facilidades, para preservação de sua saúde física e mental e seu aperfeiçoamento moral, intelectual, espiritual e social, em condições de liberdade e dignidade. (BRASIL, 2003, s.p,) 
Verifica-se, portanto, o fortalecimento da garantia, ao idoso, dos direitos fundamentais e da preservação da sua saúde física e mental. Já em relação às obrigações do Poder Público, e respectivas políticas sociais e recursos, a lei (BRASIL, 2003) também apresenta algumas determinações:

Art. 3- É obrigação da família, da comunidade, da sociedade e do Poder Público assegurar ao idoso, com absoluta prioridade, a efetivação do direito vida, à saúde, à alimentação, à educação, à cultura, ao esporte, ao lazer, ao trabalho, à cidadania, à liberdade, à dignidade, ao respeito e à convivência familiar e comunitária.

Parágrafo único. A garantia de prioridade compreende:

$\S 1^{\circ} \mathrm{A}$ garantia de prioridade compreende:

I - atendimento preferencial imediato e individualizado junto aos órgãos públicos e privados prestadores de serviços à população;

II - preferência na formulação e na execução de políticas sociais públicas específicas;

III - destinação privilegiada de recursos públicos nas áreas relacionadas com a proteção ao idoso; [...] (BRASIL, 2003, s.p)

No Brasil, nos últimos anos, as discussões sobre acessibilidade e mobilidade urbana têm estado em pauta nas prefeituras e, em especial, no meio acadêmico. Todavia, apesar de a mobilidade ser um assunto cada vez mais recorrente, ela ainda tem sido muito abordada sob a ótica do automóvel. A acessibilidade, por sua vez, está mais ligada ao ambiente arquitetônico, e mesmo quando relacionada ao ambiente urbano, o foco é as pessoas com deficiência.

Neste artigo trataremos de mobilidade ativa no âmbito do pedestre, ou seja, o ato de caminhar. Usaremos, portanto, o conceito de caminhabilidade, "que trata deste tema ao definir atributos, no ambiente construído, convidativos ao caminhar, tais como acessibilidade, conforto ambiental, atratividades de usos, permeabilidade do tecido urbano, entre outros" (ANDRADE, LINKE, 2017, p. 6). "O estudo da caminhabilidade permite investigar o quão caminhável pode ser uma rua, um bairro ou uma cidade" (SUTTI, PAIVA, 2017, p.186) e precisa ser feito com intervalos mais curtos de tempo, a ser definido conforme a necessidade local.

Tal estudo é um processo em construção que precisa ser refinado por meio de diversas experiências que levem em conta variáveis objetivas e subjetivas, considerando sua própria dificuldade de classificação e de definição do que é caminhável. (SUTTI, PAIVA, 2017, p.186)

Quanto a acessibilidade usaremos o conceito explicitado por Rodrigues (2017):

Acessibilidade é, em primeiro lugar, um atributo dos lugares. No caso do ambiente urbano, é uma propriedade relacionada às facilidades que possibilitam autonomia, relativa rapidez e, principalmente, segurança nos 
deslocamentos desejados. Esse conceito pode ser complementado pela noção de acessibilidade universal, em ressalva à associação restrita que geralmente se faz do termo aos elementos da infraestrutura para a locomoção apenas de pessoas com deficiência. Nesta perspectiva, caminhabilidade e acessibilidade, como dimensões da vida urbana, são indissociáveis. (RODRIGUES, 2017, p.119)

A caminhabilidade e a acessibilidade estão totalmente ligadas à escala humana. Somente através do entendimento de como o pedestre utiliza o espaço e de suas limitações físicas e cognitivas, é possível fazer uma cidade para pessoas, onde exista a acessibilidade plena garantindo o direito de ir e vir.

Gehl (2015) discursa sobre a importância da escala humana para a concepção dos projetos e a mudança do modo de vida nas cidades:

Se quisermos estimular o tráfego de pedestres e de bicicletas e realizar o sonho de cidades vivas, seguras, sustentáveis e saudáveis, precisamos começar pelo perfeito conhecimento da escala humana. Compreender a escala do corpo humano é importante se quisermos trabalhar de forma objetiva e adequada com ela, assim como abordar a interação entre a escala do pequeno e do lento e outras escalas também em funcionamento. (GEHL, 2015, p.55)

Todavia, a inserção da escala humana nas ruas das cidades brasileiras é um desafio. Rodrigues (2017, p. 118) comenta que "não há políticas efetivas e sistemáticas voltadas para pedestres, apesar do fato de $23,4 \%$ de todas as viagens no país serem realizadas a pé". O pedestre não é o elemento principal no que diz respeito à mobilidade, como é reforçado por Vasconcellos (2017):

Embora caminhar sempre tenha sido a forma universal de deslocamento das pessoas, os planos e projetos de transporte e trânsito feitos no Brasil historicamente ignoraram o ato de deslocar a pé. A primeira constatação da falta de prioridade foi a decisão de atribuir ao proprietário do lote a responsabilidade de construir e cuidar das calçadas. Esta decisão revela que o ato de caminhar não é considerado tema público, mas sim privado. Em consequência disso, toda a engenharia viária foi desenvolvida com atenção exclusiva à pista dos veículos. (VASCONCELLOS, 2017, p.46)

É preciso repensar o planejamento da cidade considerando a qualidade das calçadas e a grande variedade de pessoas que caminham nas ruas. "As novas políticas públicas devem levar em consideração a mobilidade urbana e, em especial, a diminuição da mobilidade dos idosos. Entretanto, a infraestrutura das cidades atuais não é projetada para atender à mobilidade dessa parcela da população [...]" (VERAS, DOMENICO, MARQUES, 2017, grifo nosso). Por outro lado, o primeiro princípio da Política Nacional de Mobilidade Urbana é a acessibilidade universal, com o objetivo de reduzir as desigualdades e promover a inclusão 
social (BRASIL, 2012). O art. $3^{\circ}$ da Lei no 10.098 afirma que "o planejamento e a urbanização das vias públicas, dos parques e dos demais espaços de uso público deverão ser concebidos e executados de forma a torná-los acessíveis para todas as pessoas, inclusive para aquelas com deficiência ou com mobilidade reduzida (BRASIL, 2000). O poder público precisa compreender os benefícios da caminhabilidade e querer tornar a cidade mais saudável e atrativa, auxiliando ainda na obtenção dos direitos do cidadão.

Rodrigues (2017) critica a posição atual dos governos sobre o assunto ao afirmar que "a precariedade de infraestrutura e de condições adequadas para acessibilidade e caminhabilidade nas cidades brasileiras é resultante do desinteresse do poder público e de suas prioridades, do baixo desenvolvimento institucional dos municípios e da capacidade técnica insuficiente das prefeituras" (RODRIGUES, 2017, p.209). Cabe a cidade criar condições de acessibilidade e mobilidade urbana, assim como sustenta Martins (2016, p.07) ao declarar que "com efeito, as cidades devem promover a integração e o bem-estar dos seus habitantes, ela deve constituir-se como um espaço vital, feito pelos seres humanos e para os seres humanos"

É importante observar que caminhar é um princípio básico. "Todos são pedestres em algum momento. $\mathrm{O}$ ato de caminhar deveria ser, portanto, mais respeitado, em vez de ser o mais negligenciado no sistema de mobilidade urbana" (DECASTRO, SALDANHA, BALASSIANO, 2017, p.209). A cidade se torna interessante quando suas ruas são interessantes e, consequentemente, se tornam seguras devido ao grande fluxo de pessoas que transitam pelas calçadas. Desta forma, é de fácil constatação que "as ruas e suas calçadas, principais locais públicos de uma cidade, são seus órgãos mais vitais" (JACOBS, 2009. p. 29), pois definem não só a forma da cidade ou do bairro, mas gera toda a interação social urbana. "Portanto, promover a caminhabilidade é uma medida-chave para levar as pessoas a ocupar o espaço público, reduzir os impactos ambientais de efeito barreira, vitalizar a economia local e a interação social” (DECASTRO, SALDANHA, BALASSIANO, 2017, p.211).

Speck (2017) apresenta a Teoria Geral da Caminhabilidade em que, a caminhada, para ser satisfatória precisa atender a quatro condições principais: ser proveitosa, segura, confortável e interessante.

\begin{abstract}
Proveitosa significa que a maior parte dos aspectos da vida cotidiana está por perto e são organizados de tal modo que uma caminhada atenda às necessidades do morador. Segura significa que a rua foi projetada para dar aos pedestres uma chance contra acidentes com automóveis: os pedestres não tem apenas que estar seguros; precisam se sentir seguros, condição ainda mais difícil de atender. Confortável significa que edifícios e paisagem conformam as ruas como 'salas de estar ao ar livre', em contraste com os imensos espaços abertos que, geralmente, não conseguem atrair pedestres. Interessante significa que as calçadas são ladeadas por edifícios singulares agradáveis e com fartura de sinais de humanidade. (SPECK, 2017, p.20-21)
\end{abstract}

É importante atentar-se para a questão da segurança colocada por Speck (2017), quando explica que uma caminhada segura está relacionada a questões físicas da via, principalmente à calçada, mas fazer com que o pedestre se sinta seguro é algo difícil de atender. A questão da segurança e consequentemente da acessibilidade a determinados locais da cidade está diretamente ligada às suas ruas e calçadas, sendo delas, dentre outros, a função de propiciar a segurança urbana. A rua torna-se atrativa quando é dotada de uma infraestrutura que garanta a segurança, tanto pelo movimento que nela existe, quanto pelos olhos atentos das pessoas que a ela observam (JACOBS, 2009). Assim, verificamos que a acessibilidade 
também está relacionada com questões psicológicas. Uma calçada é acessível quando consegue proporcionar segurança física, boa infraestrutura e sensação de seguridade.

Dessa forma, é nítida a necessidade de estudos e políticas públicas, sobretudo no que diz respeito à acessibilidade e à mobilidade urbana, para que a sociedade, em especial a parcela idosa, tenha autonomia para se locomover nas ruas e poder exercer seu direito de estar inserida na vida social da cidade.

No município de Campos dos Goytacazes, essa realidade parece não ser diferente, porque a cidade apresenta muitas barreiras ao idoso, principalmente nos contextos físico, arquitetônico, urbanístico e comunicacional. É importante ressaltar que o Art. 75 do Código de Obras obriga o proprietário do lote a pavimentar e preservar a calçada em frente ao seu lote, podendo a prefeitura, no Art. 76 , definir ou não uma padronização da pavimentação. Esse aspecto da legislação gera diferença no caminho do pedestre e proporciona a má adequação da acessibilidade universal na calçada.

Por isso, esse estudo tem como objetivo uma análise da qualidade da infraestrutura atual da calçada de uma via, considerando os aspectos da acessibilidade e da caminhabilidade para idoso no município de Campos dos Goytacazes. Acredita-se que esse trabalho possa contribuir par a conscientização do problema e para a adoção de medidas de acessibilidade e mobilidade urbana em prol da qualidade de vida do idoso na cidade.

\section{METODOLOGIA}

A metodologia desta pesquisa foi dividida em quatro etapas. A primeira consistiu na revisão bibliográfica sobre a temática, para compreender como ela está sendo entendida e registrada, por meio de livros e artigos científicos de diversos autores.

A segunda etapa foi a pesquisa documental, em que foram estudadas as legislações vigentes no âmbito municipal da cidade de Campos dos Goytacazes/RJ, e nacional; entendendo como as leis tratam da questão do idoso (Estatuto do Idoso, Lei $\mathrm{n}^{\circ} 10.741$ de $1^{\circ} 10$ de outubro de 2003), da acessibilidade (Lei $n^{\circ} 10.098$ de 19 de dezembro de 2000 e a NBR 9050/2015), da mobilidade urbana (Política Nacional de Mobilidade Urbana, Lei no 12.587 de 03 de janeiro de 2012) e da infraestrutura urbana do Município de Campos dos Goytacazes (Código de Obras, Lei n ${ }^{\circ}$ 6.692, de 28 de novembro de 1998 ).

Em uma terceira etapa, foram examinados diferentes métodos de análise da caminhabilidade, em diferentes escalas e lugares, com a finalidade de selecionar um método já utilizado anteriormente e que pudesse ser aplicado nessa pesquisa. Foi, portanto, escolhido o método utilizado por Silva, Silva e Providelo (2017) que fez um estudo da caminhabilidade com foco nas pessoas idosas, sendo o mesmo objetivo dessa pesquisa. Os autores analisaram duas avenidas da cidade de São Carlos, localizada no estado de São Paulo. Para isso, eles usaram 13 indicadores (Tabela 02) e dividiram a análise por "segmento", que corresponde ao percurso de calçada entre duas esquinas, e "travessia". Portanto, os indicadores de 1 a 11 são de cada trecho de segmento, enquanto os de números 12 e 13 são de travessias. O resultado final de cada indicador é a média das notas atribuídas aos indicadores analisados, por uma equipe técnica, em cada segmento e travessia. 
Tabela 02 - Critérios de Avaliação (Fonte: Silva, Silva e Providelo, 2017)

\begin{tabular}{|c|c|c|c|}
\hline \multicolumn{4}{|l|}{ Segmento } \\
\hline Indicador & 1 - Péssimo & 3 - Regular & 5 - Ótimo \\
\hline $\begin{array}{l}\text { 1. Infraestrutura para } \\
\text { pedestres }\end{array}$ & $\begin{array}{l}\text { Sem calçada em todo } \\
\text { segmento }\end{array}$ & $\begin{array}{l}\text { Calçada em } 50 \% \text { do } \\
\text { segmento }\end{array}$ & $\begin{array}{l}\text { Calçada em todo o } \\
\text { segmento }\end{array}$ \\
\hline 2. Largura da calçada & Menor que $1 \mathrm{~m}$ & Cerca de $1,5 \mathrm{~m}$ & Maior que $2 \mathrm{~m}$ \\
\hline $\begin{array}{l}\text { 3. Obstáculos sobre a } \\
\text { calçada }\end{array}$ & $\begin{array}{l}\text { Impedem totalmente } \\
\text { a passagem }\end{array}$ & $\begin{array}{l}\text { Bloqueiam } 50 \% \text { da } \\
\text { faixa de circulação }\end{array}$ & Não existem \\
\hline 4. Piso da calçada & $\begin{array}{l}\text { Piso com defeitos em } \\
\text { todo o segmento ou sem } \\
\text { piso }\end{array}$ & $\begin{array}{l}\text { Piso com defeitos em } \\
50 \% \text { do segmento ou de } \\
\text { material escorregadio }\end{array}$ & $\begin{array}{l}\text { Piso sem defeitos e com } \\
\text { antiderrapante }\end{array}$ \\
\hline 5. Arborização & $\begin{array}{l}\text { Sem arborização - } 0 \% \\
\text { com sombra }\end{array}$ & $\begin{array}{l}\text { Sombra em } 50 \% \text { do } \\
\text { segmento }\end{array}$ & $\begin{array}{l}\text { Sombra em } 100 \% \text { do } \\
\text { segmento }\end{array}$ \\
\hline 6. Segurança & $\begin{array}{l}\text { Sensação de } \\
\text { inseguridade total }\end{array}$ & Sensação neutra & $\begin{array}{l}\text { Sensação de total } \\
\text { segurança }\end{array}$ \\
\hline $\begin{array}{l}\text { 7. Conflitos com } \\
\text { veículos } \\
\text { sobre a calçada }\end{array}$ & $\begin{array}{l}\text { Mais de } 75 \% \text { do } \\
\text { segmento com guias } \\
\text { rebaixadas }\end{array}$ & $\begin{array}{l}\text { Entre } 25 \% \text { e } 50 \% \text { do } \\
\text { segmento com guias } \\
\text { rebaixadas }\end{array}$ & $\begin{array}{l}\text { Sem guias rebaixadas } \\
\text { em todo o segmento }\end{array}$ \\
\hline $\begin{array}{l}\text { 8. Atratividade do } \\
\text { ambiente }\end{array}$ & $\begin{array}{l}\text { Ambiente muito } \\
\text { desagradável, sem } \\
\text { bancos ou áreas para } \\
\text { descansar }\end{array}$ & Ambiente neutro & $\begin{array}{l}\text { Ambiente muito } \\
\text { agradável, com bancos } \\
\text { e áreas para descansar }\end{array}$ \\
\hline $\begin{array}{l}\text { 9. Declividade } \\
\text { longitudinal }\end{array}$ & $\begin{array}{l}\text { Declive muito } \\
\text { acentuado }\end{array}$ & Declive médio & Segmento plano \\
\hline $\begin{array}{l}\text { 10. Acessibilidade } \\
\text { universal no segmento }\end{array}$ & $\begin{array}{l}\text { Degraus maiores que } 10 \\
\mathrm{~cm}\end{array}$ & $\begin{array}{l}\text { Desníveis entre } 2 \text { e } 5 \\
\mathrm{~cm}\end{array}$ & $\begin{array}{l}\text { Sem desníveis e de } \\
\text { acordo com as normas } \\
\text { de acessibilidade }\end{array}$ \\
\hline $\begin{array}{l}\text { 11. Exposição ao } \\
\text { tráfego }\end{array}$ & $\begin{array}{l}\text { Via arterial, muito } \\
\text { tráfego, incluindo } \\
\text { veículos de grande } \\
\text { porte }\end{array}$ & $\begin{array}{l}\text { Via coletora, tráfego } \\
\text { médio, poucos veículos } \\
\text { de grande porte }\end{array}$ & $\begin{array}{l}\text { Via local, veículos leves } \\
\text { com velocidade menor } \\
\text { que } 35 \mathrm{~km} / \mathrm{h}\end{array}$ \\
\hline \multicolumn{4}{|c|}{$\begin{array}{l}\text { Travessias semaforizadas (variáveis que compõem o indicador "12. Segurança na tra- } \\
\text { vessia") }\end{array}$} \\
\hline $\begin{array}{l}\text { Variáveis que } \\
\text { compõem o indicador } \\
\text { "Segurança na } \\
\text { travessia" }\end{array}$ & 1 - Péssimo & 3 - Regular & 5 - Ótimo \\
\hline Tipo de semáforo & $\begin{array}{l}\text { Sem faixa de pedestre, } \\
\text { sem tempo e sem } \\
\text { botoeira para pedestres }\end{array}$ & $\begin{array}{l}\text { Com faixa de pedestre } \\
\text { com manutenção } \\
\text { regular, sem tempo e } \\
\text { sem botoeira para } \\
\text { pedestres }\end{array}$ & $\begin{array}{l}\text { Com faixa de pedestre } \\
\text { com manutenção em } \\
\text { dia, tempo e botoeira } \\
\text { para pedestres }\end{array}$ \\
\hline Tempo de travessia & $\begin{array}{l}\text { Tempo insuficiente para } \\
\text { travessia de um idoso } \\
\text { sem dificuldade de } \\
\text { locomoção }\end{array}$ & $\begin{array}{l}\text { Com faixa de pedestre } \\
\text { com manutenção } \\
\text { regular, sem tempo e } \\
\text { sem botoeira para } \\
\text { pedestres }\end{array}$ & $\begin{array}{l}\text { Tempo suficiente para a } \\
\text { travessia de um idoso } \\
\text { com dificuldade de } \\
\text { locomoção }\end{array}$ \\
\hline
\end{tabular}




\section{Travessias não semaforizadas (variáveis que compõem o indicador "12. Segurança na travessia")}

\begin{tabular}{|l|l|l|l|}
\hline $\begin{array}{l}\text { Variáveis que } \\
\text { compõem o indicador } \\
\text { "Segurança na } \\
\text { travessia" }\end{array}$ & $\mathbf{1}$ - Péssimo & $\mathbf{3}$ - Regular & $\mathbf{5}$ - Ótimo \\
\hline $\begin{array}{l}\text { Velocidade média na } \\
\text { transversal }\end{array}$ & $\begin{array}{l}\text { Velocidades maiores } \\
\text { que } \\
60 \mathrm{~km} / \mathrm{h}\end{array}$ & $\begin{array}{l}\text { Velocidades entre } 40 \mathrm{e} \\
50 \mathrm{~km} / \mathrm{h}\end{array}$ & $\begin{array}{l}\text { Velocidades menores } \\
\text { que } \\
30 \mathrm{~km} / \mathrm{h}\end{array}$ \\
\hline $\begin{array}{l}\text { Largura da via } \\
\text { transversal }\end{array}$ & Maior que $12 \mathrm{~m}$ & Igual a $10 \mathrm{~m}$ & Menor que $8 \mathrm{~m}$ \\
\hline $\begin{array}{l}\text { Tráfego na via } \\
\text { transversal }\end{array}$ & $\begin{array}{l}\text { Via arterial, muito } \\
\text { tráfego, } \\
\text { incluindo veículos de } \\
\text { grande porte }\end{array}$ & $\begin{array}{l}\text { Via coletora, tráfego } \\
\text { médio, } \\
\text { poucos veículos de } \\
\text { grande } \\
\text { porte }\end{array}$ & $\begin{array}{l}\text { Via local, veículos leves } \\
\text { com } \\
\text { velocidade menor que } \\
35 \mathrm{~km} / \mathrm{h}\end{array}$ \\
\hline Visibilidade & $\begin{array}{l}\text { Obstáculos e veículos } \\
\text { estacionados bloqueiam } \\
\text { a } \\
\text { visibilidade do tráfego } \\
(0 \% \\
\text { de visibilidade })\end{array}$ & $\begin{array}{l}\text { O pedestre possui } 50 \% \\
\text { da } \\
\text { visibilidade do tráfego }\end{array}$ & $\begin{array}{l}\text { O pedestre tem boa } \\
\text { visibilidade do tráfego } \\
(100 \% \\
\text { de visibilidade })\end{array}$ \\
\hline
\end{tabular}

\section{Travessias (avaliação unificada)}

\begin{tabular}{|l|l|l|l|}
\hline Indicador & $\mathbf{1}$ - Péssimo & $\mathbf{3}$ - Regular & $\mathbf{5}$ - Ótimo \\
\hline $\begin{array}{l}\text { 13. Infraestrutura para } \\
\text { pedestres }\end{array}$ & $\begin{array}{l}\text { Sem rampas e sem faixa } \\
\text { de pedestre }\end{array}$ & $\begin{array}{l}\text { Rampas inadequadas, } \\
\text { com faixa de pedestre } \\
\text { em boa condição de } \\
\text { manutenção }\end{array}$ & $\begin{array}{l}\text { Faixa de pedestre com } \\
\text { travessia elevada }\end{array}$ \\
\hline
\end{tabular}

$\mathrm{Na}$ quarta etapa, foi definido um recorte espacial, que consistiu em um trecho da área central do município de Campos dos Goytacazes, conforme será justificado e evidenciado mais adiante. Em seguida, houve a execução da pesquisa de campo, seguindo o modelo apresentado anteriormente.

Por fim, foram desenvolvidas algumas análises e, posteriormente, tecidas as considerações finais sobre o trabalho.

\section{RESULTADOS E DISCUSSÃO}

O município de Campos dos Goytacazes (Figura 01) está localizado no norte do Estado do Rio de Janeiro. Segundo o censo de 2010 do IBGE, possui uma população de 463.731 habitantes (com estimativa de 503.424 habitantes no ano de 2018). É o município 


\section{PERSPECTIVAS online CIENCIAS HUMANAS ESOCIAIS APLICADAS}

mais populoso da região, o $7^{\circ}$ no Estado e o $47^{\circ}$ no Brasil.

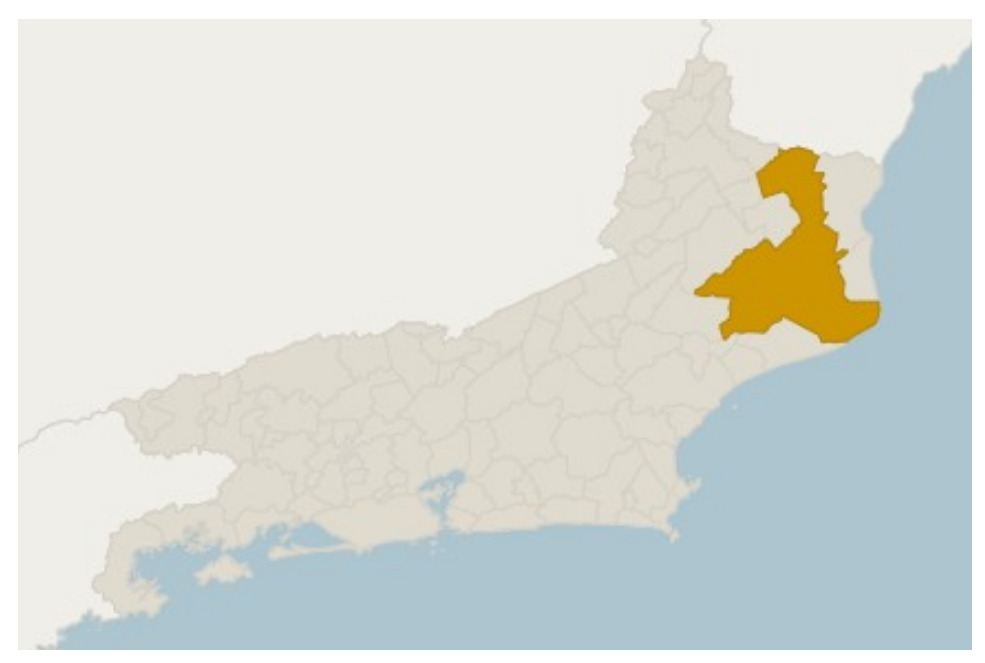

Figura 01 - Localização de Campos dos Goytacazes no RJ (Fonte: IBGE, 2019)

Para o estudo, observou-se que a melhor área para a análise consistiu no Centro da cidade (demarcado em vermelho na Figura 02), por ser um polo de comércio e serviço para pessoas provenientes de diferentes bairros e considerando a fala de Speck (2017, p.226) ao afirmar que "o centro é a única parte da cidade que pertence a todos. Não importa onde você more; o centro também é seu. Investir no centro da cidade é a única forma, baseada em um local, de beneficiar todos os cidadãos de uma só vez." Para definir o recorte do trecho estudado, foi feita uma observação quanto à oferta de serviços diferenciados e fortemente utilizados pela população idosa. Assim, foi escolhido um trecho da Av. José Alves de Azevedo, entre a Av. 28 de Março e a Rua João Pessoa, que contempla o Hospital dos Plantadores de Cana, a Rodoviária Roberto Silveira e o Mercado Municipal, totalizando um percurso de aproximadamente $900 \mathrm{~m}$, dividido em 5 segmentos (Figura 03). A direção do trajeto durante a análise teve início no seguimento 1 e a finalização, no segmento 5 .

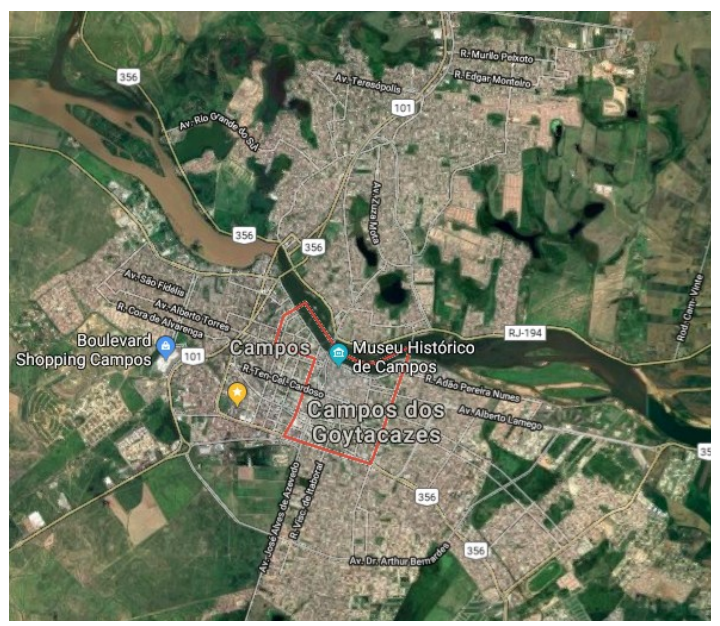

Figura 02 - Centro da cidade de Campos dos Goytacazes (Fonte: Google Maps, 2019) 


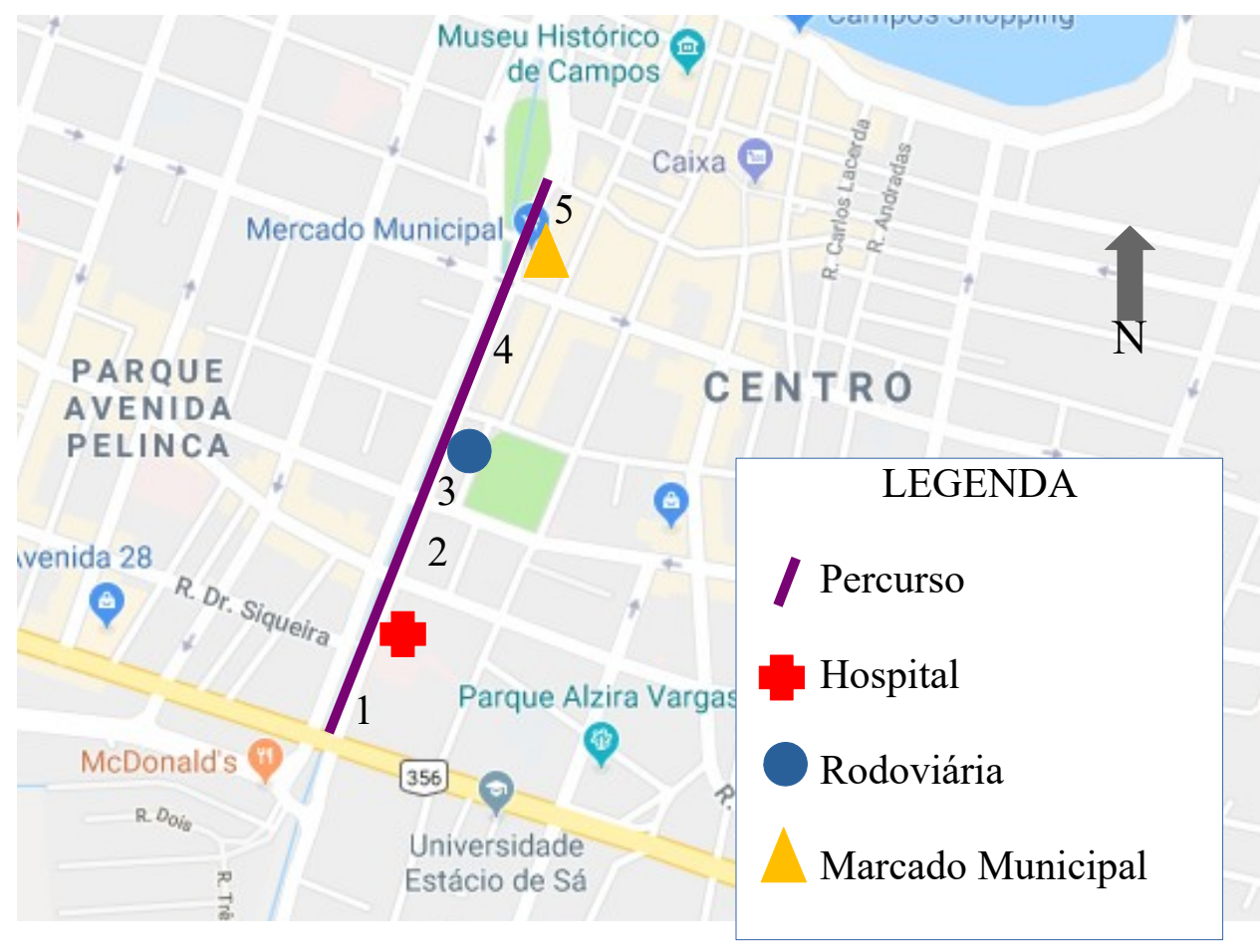

Figura 04 - Percurso analisado no centro da cidade de campos dos Goytacazes (Fonte: Google Maps, 2019. Modificado)

O método de avaliação utilizou um sistema de cinco notas, apresentando a seguinte escala: 1 = péssimo; 2 = ruim; $3=$ regular; $4=$ bom; $5=$ ótimo e aplicou os mesmos critérios utilizados por Silva, Silva e Providelo (2017) que são apresentados no Anexo I. Conforme mencionado, a análise considerou cada segmento em conjunto com a travessia da rua seguinte, com 11 indicadores para análise dos segmentos e 2 para travessias (segurança na travessia e acessibilidade universal na travessia). O indicador de número 12, "segurança na travessia", teve duas variações que dependiam da presença ou não de semáforo. Foram considerados semáforos exclusivos de pedestres ou não. Os indicadores foram avaliados de forma individual em cada segmento e travessia. A pesquisa foi realizada com base na bagagem técnica, bibliográfica e profissional do avaliador Jefferson Carvalho, no dia 12 de março de 2019 com início às $11 \mathrm{~h} 52 \mathrm{~min}$ e término às $12 \mathrm{~h} 21 \mathrm{~min}$ (horário de Brasília). A avaliação foi feita a pé e além de questões técnicas considerou o caminhar dos idosos, através de observação, que transitavam no momento pelo percurso.

A Tabela 03 ilustra as notas conferidas a cada indicador, por seguimento e travessia. As travessias avaliadas foram as presentes entre dois seguimentos de calçada no recorte estudado. 
Tabela 03 - Notas conferidas a cada indicador (Fonte: Acervo pessoal, 2019)

\begin{tabular}{|c|c|c|c|c|c|c|c|}
\hline Indicadores & Seg. 01 & Seg & 02 & Seg. $C$ & & Seg. 04 & Seg. 05 \\
\hline 1 - Infraestrutura & 5 & & 5 & & 5 & 5 & 5 \\
\hline 2 - Largura da calçada & 4 & & 4 & & 5 & 4 & 5 \\
\hline 3 - Obstáculos sobre a calçada & 5 & & 5 & & 4 & 2 & 2 \\
\hline 4 - Piso da calçada & 4 & & 4 & & 5 & 3 & 1 \\
\hline 5 - Arborização & 2 & & 1 & & 1 & 1 & 1 \\
\hline 6 - Seguridade & 3 & & 3 & & 3 & 3 & 2 \\
\hline 7 - Conflitos com veículos sobre a calçada & 1 & & 5 & & 4 & 1 & 1 \\
\hline 8 - Atratividade do ambiente & 1 & & 1 & & 1 & 1 & 1 \\
\hline 9 - Declividade longitudinal & 4 & & 4 & & 5 & 5 & 5 \\
\hline 10 - Acessibilidade universal no segmento & 4 & & 3 & & 2 & 3 & 3 \\
\hline 11 - Exposição ao tráfego & 1 & & 1 & & 1 & 1 & 1 \\
\hline \multicolumn{3}{|l|}{ Indicadores } & \multicolumn{2}{|c|}{ Trav. 02} & & rav. 03 & Trav. 04 \\
\hline 12.1 - Tipo de semáforo & & 3 & & 3 & & 0 & 3 \\
\hline 12.2 - Tempo de travessia & & 3 & & 3 & & 0 & 3 \\
\hline 12.3 - Velocidade média na transversal & & 3 & & 3 & & 4 & 3 \\
\hline 12.4 Largura da via transversal & & 5 & & 1 & & 4 & 4 \\
\hline 12.5Tráfego na via transversal & & 3 & & 3 & & 4 & 3 \\
\hline 12.6 Visibilidade & & 5 & & 5 & & 2 & 3 \\
\hline 13 - Acessibilidade universal na travessia & & 3 & & 3 & & 2 & 1 \\
\hline
\end{tabular}

Para o resultado final por indicador (Gráfico 01), foi feita uma média das avaliações dos 5 seguimentos estudados. Em geral, as notas se mostraram satisfatórias para a análise do recorte estudado. Os piores índices observados foram: "Exposição ao tráfego" e "Atratividade do ambiente", pois ambos obtiveram nota 1,0.

Através do estudo da Lei de Parcelamento do Solo do município (Lei 7.975 de 31 de março de 2008), foi possível constatar que o trecho da análise está inserido em uma via arterial, possuindo um grande volume de tráfego. Recebe, inclusive, ônibus de transporte municipal, intermunicipal e interestadual. Dessa forma, o resultado esperado para o indicador "exposição ao tráfego" foi confirmado durante a análise. 


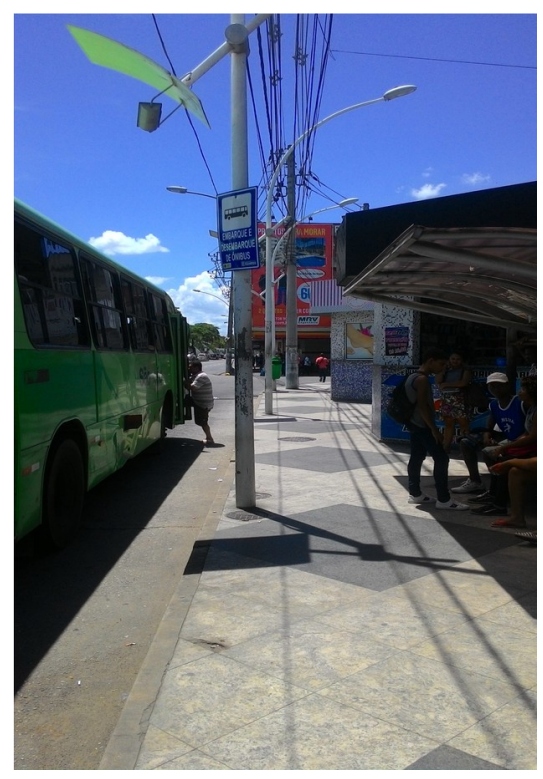

Figura 04 - Parada de ônibus no segmento 3 (Fonte: Acervo pessoal, 2019)

O percurso não é atrativo para permanência. Na maioria dos espaços, não há lugar para se sentar, com exceção das paradas de ônibus.

Os resultados insatisfatórios dos indicadores "Arborização" (nota 1,2), "Acessibilidade universal na travessia" (nota 2,25), "Conflitos com veículos sobre a calçada" (nota 2,4), "Seguridade" (nota 2,8) mostram que o trecho analisado necessita de muitas melhorias para se tornar caminhável, principalmente para pessoas idosas.

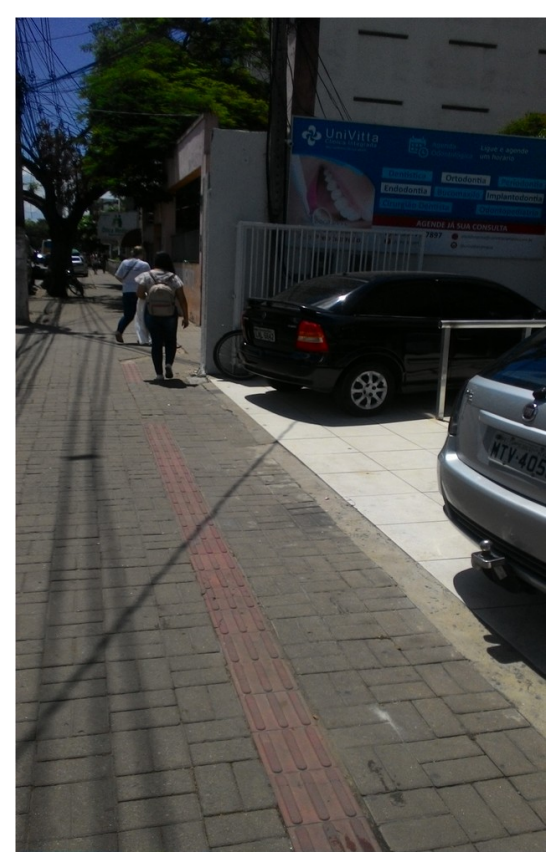

Figura 05 - Conflito com veículos sobre a calçada no segmento 1 (Fonte: Acervo pessoal, 2019) 
Os itens "Acessibilidade universal no segmento" (nota 3,0), "Segurança na travessia" (nota 3,29), "Piso da calçada" (nota 3,4) e "Obstáculos sobre a calçada" (nota 3,6) foram classificados entre regular e bom. São indicadores que podem ser melhorados, de forma rápida, através de: manutenção e adequação do piso; construção de rampas de acesso com dimensionamento e inclinação correta; redução de percurso da travessia ou a escolha por travessia elevada; inserção e conservação de mobiliário urbano; e, sempre que possível, a divisão da calçada em faixas livre, de serviço e de acesso, conforme a NBR 9050/2015.

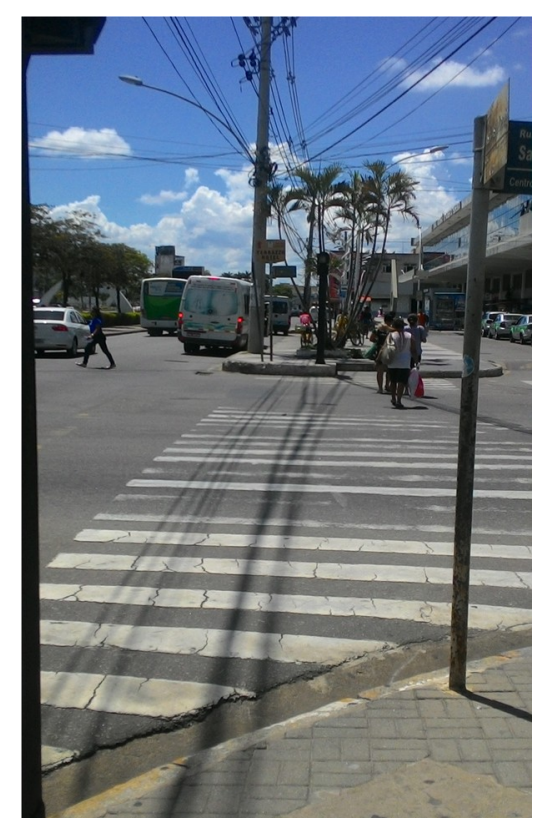

Figura 06 - Travessia entre os seguimentos 2 e 3 (Fonte: Acervo pessoal, 2019)

Gráfico 01 - Resultado por Indicador (Fonte: Acervo pessoal, 2019)

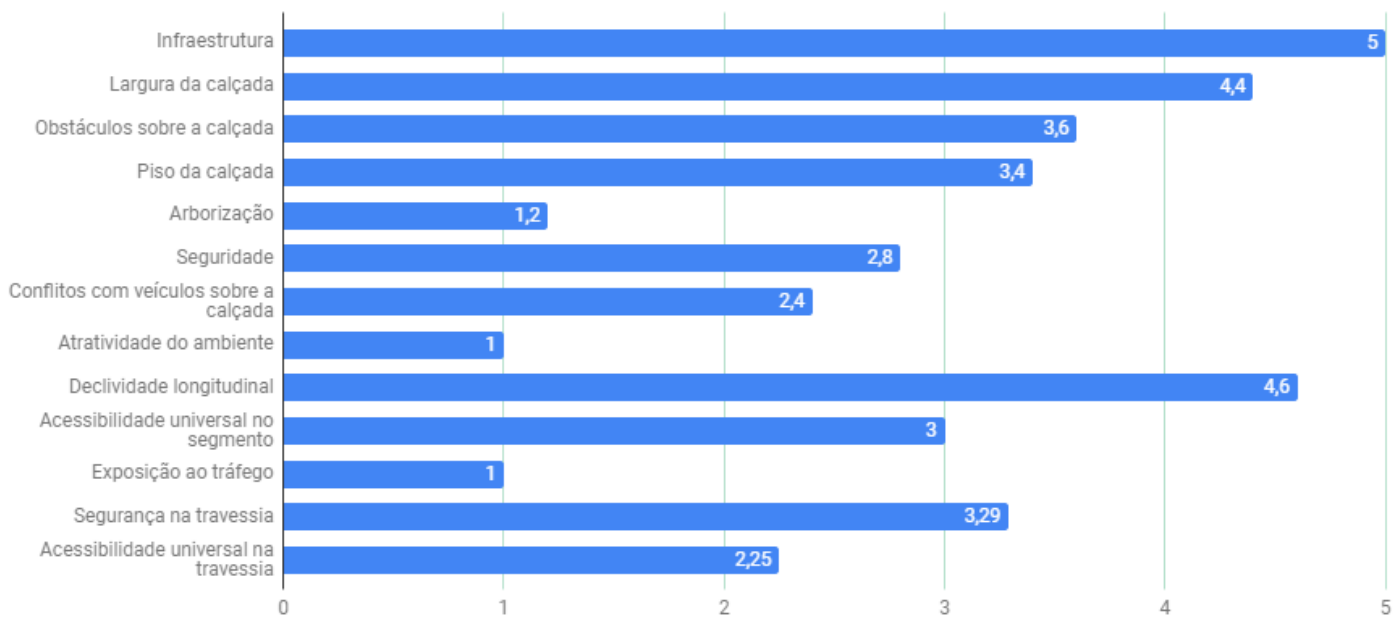

Como esperado, a melhor avaliação foi do indicador "Infraestrutura para pedestres", que examinou a presença de calçada na via, obtendo nota máxima $(5,0)$ por se tratar de uma área consolidada e de grande circulação de veículos e pedestres. Outros indicadores também obtiveram uma avaliação satisfatória como "Declividade longitudinal" (nota 4,6), que não alcançou nota máxima pelo rebaixamento incorreto de alguns acessos de veículos. Seguido 
pela "Largura da calçada" (nota 4,4) cuja presença de alguns trechos com largura de aproximadamente, ou menor, de 1 metro cria pontos críticos durante a caminhabilidade. Em parte do segmento 4, por exemplo, é necessário andar em um espaço com aproximadamente $50 \mathrm{~cm}$, devido ao alinhamento de um lote que se apresenta bem próximo a rua, ou até mesmo andar na rua ao desviar de poste de energia.

\section{CONCLUSÕES}

A análise realizada evidencia que há muitos problemas a serem resolvidos em relação às condições necessárias para a caminhabilidade e a acessibilidade dos idosos na cidade de Campos dos Goytacazes. Acredita-se que, apesar das diferenças entre as ruas da cidade, a análise feita conseguiu exemplificar um breve panorama desses aspectos.

Certamente que algumas vias resultariam em indicadores com uma avaliação mais satisfatória, enquanto outras altamente insatisfatórias. Todavia, o trecho escolhido buscou ser democrático, ao escolher uma área central e grande utilização, para tentar evidenciar a realidade existente e servir como base para um estudo de outras vias.

Existem diversos outros indicadores quando se trata de caminhabilidade, mas a escolha de reproduzir os mesmos itens apresentados por Silva, Silva e Providelo (2017) se deu pelo objetivo da análise em estudar a qualidade da infraestrutura atual da via com relação à caminhabilidade focada nos idosos. Sendo interessante uma avaliação técnica e entendendo que outros tipos de análise podem complementar esta pesquisa.

Os indicadores apresentados exigem uma avaliação objetiva e quantitativa; porém, uma avaliação em que houvesse a participação do próprio usuário idoso, com o registro de suas percepções, sentimentos e ações, pode contribuir fortemente para o estudo, por entender que as relações de escolha do ato de caminhar pelos indivíduos servem de base para a análise proposta. Todavia, a proposta aqui apresentada se baseou em uma análise mais técnica através de critérios pré definidos.

De qualquer modo, verifica-se o quão desafiador pode ser a vivência desses espaços por parte dos idosos, já que há uma dificuldade no atendimento a todos os critérios considerados importantes para a autonomia e segurança no caminhar desses usuários.

A importância de avaliar a caminhabilidade para grupos distintos é evidenciada pelo fato de que cada grupo é único e, mesmo dentro de seu conjunto, cada indivíduo possui uma particularidade. As barreiras encontradas pelos idosos são diferentes das encontradas pela população jovem, por exemplo, devido as suas limitações de locomoção, velocidade e muitas vezes visual. Assim, a pesquisa, ao apresentar indicadores de ordem física, serve de base para a decisão de políticas públicas que busquem melhorar a situação do cenário urbano, tornandoo mais inclusivo, acessível e caminhável.

A acessibilidade universal na área selecionada é um item que se mostrou crítico, tanto na travessia quanto no seguimento, com o resultado da análise e precisa ser adequada conforme a NBR 9050 (ABNT, 2015), a Lei n ${ }^{\circ} 10.098$ de 19 de dezembro de 2000 e a Política Nacional de Mobilidade Urbana (Lei $n^{\circ} 12.587$ de 3 de janeiro de 2012). Portanto, esse aspecto mais físico dos indicadores contribui na melhoria da caminhabilidade para outros grupos sociais ao passo que indica aspectos gerais para a melhoria da acessibilidade urbana. A presente análise serve, ainda, como consulta para um futuro estudo sobre a mobilidade ativa na cidade de Campos dos Goytacazes. 


\section{REFERÊNCIAS}

ASSOCIAÇÃO BRASILEIRA DE NORMAS TÉCNICAS (ABNT). NBR 9050: Acessibilidade a edificações, mobiliário, espaços e equipamentos urbanos. Rio de Janeiro, set. 2015.

AGÊNCIA DE NOTÍCIAS IBGE. PNAD 2016: população idosa cresce 16,0\% frente a 2012 e chega a 29,6 milhões. Disponível em: https://agenciadenoticias.bge.gov.br/agencia-sala-de-imprensa/2013-agenciade-noticias/releases/18263-pnad-2016-populacao-idosa-cresce-16-0-frente-a-2012-e-chega-a-29-6-milhoes . Acesso: 05 mar. 2019.

BRASIL. Lei n $\mathbf{n}^{\mathbf{1 0}} \mathbf{1 0 9 8}$, de 19 de dezembro de 2000. Promoção da acessibilidade das pessoas portadoras de deficiência ou com mobilidade reduzida, e dá outras providências. Disponível em: http://www.planalto.gov.br/ ccivil 03/Leis/L10098.htm . Acesso: 04 mar. 2019.

Lei $\mathbf{n}^{\mathbf{0}}$ 10.741, de $1^{\mathrm{o}}$ de outubro de 2003. Estatuto do Idoso. Disponível em: http://www.planalto.gov.br/ccivil 03/Leis/2003/L10.741.htm . Acesso: 04 mar. 2019.

. Lei no 12.587, de 3 de janeiro de 2012. Política Nacional de Mobilidade Urbana . Disponível em: http:/www.planalto.gov.br/ccivil 03/ ato2011-2014/2012/lei/112587.htm . Acesso: 04 mar/2019.

CAMPOS DOS GOYTACAZES. Lei $\mathbf{n}^{\mathbf{0}}$ 6.692, de 28 de novembro de 1998. Código de Obras do Município de Campos dos Goytacazes. Disponível em: http://www.campos.ri.gov.br . Acesso: 04 mar. 2019.

. Lei no 7.935, de 31 de março de 2008. Lei de Parcelamento do Solo do Município de Campos dos Goytacazes. Disponível em: http://www.campos.rj.gov.br. Acesso: 04 mar. 2019.

DECASTRO, Juliana; SALDANHA, Luiz; BALASSIANO, Ronaldo. Caminhabilidade: expressão do metabolismo urbano. In: ANDRADE, V. LINKE, C. C. (Orgs). Cidades de Pedestres: A caminhabilidade no Brasil e no mundo. $1^{\text {a }}$ ed. Rio de Janeiro: Babilonia Cultura Editorial. 2017.

GEHL, Jean. Cidade para pessoas. $3^{\text {a }}$ ed. São Paulo: Perspectiva, 2015.

INTITUTO BRASILEIRO DE GEOGRAFIA E ESTAÍSTICA (IBGE). Cidades e Estados. Disponível em: https:/www.ibge.gov.br/cidades-e-estados/rj/campos-dosgoytacazes.html . Acesso:16 mar. 2019.

JACOBS, Jane. Morte e vida das grandes cidades. $2^{\text {a }}$ ed. São Paulo: Editora WMF Martins Fontes, 2009 - (Coleção mundo da arte).

MARTINS, Marcelo Henrique. O mal-estar na cidade: O sentido da urbanização em bairros periféricos. Araraquara: Unesp, 2016.

RODRIGUES, Jociano Martins. Acessibilidade, caminhabilidade e políticas para portadores de deficiência no Brasil. In: ANDRADE, V. LINKE, C. C. (Orgs). Cidades de 
Pedestres: A caminhabilidade no Brasil e no mundo. $1^{\mathrm{a}}$ ed. Rio de Janeiro: Babilonia Cultura Editorial. 2017.

Sistema IBGE de Recuperação Automática (SIDRA). Censo Demográfico 2010. Disponível em: https://sidra.ibge.gov.br/pesquisa/censo-demografico/demografico-2010/ universo-caracteristicas-da-populacao-e-dos-domicilios . Acesso: 05 mar. 2019.

SILVA, Antônio Nélson Rodrigues da; SILVA, Denise Capasso da; PROVIDELO, Janice Kirner. Cminhabilidade em um cenário de envelheciemnto populacional. In: ANDRADE, V. LINKE, C. C. (Orgs). Cidades de Pedestres: A caminhabilidade no Brasil e no mundo. $1^{\mathrm{a}}$ ed. Rio de Janeiro: Babilonia Cultura Editorial. 2017.

VASCONCELLOS, Eduardo Alcântara de. Andar nas Cidades do Brasil. In: ANDRADE, V. LINKE, C. C. (Orgs). Cidades de Pedestres: A caminhabilidade no Brasil e no mundo. $1^{\mathrm{a}}$ ed. Rio de Janeiro: Babilonia Cultura Editorial. 2017.

VERAS, Mariana; DOMENICO, Marlise Di; MARQUES, Karina do Valle. O transporte dentro da perspectiva ambiental da saúde. In: ANDRADE, V. LINKE, C. C. (Orgs). Cidades de Pedestres: A caminhabilidade no Brasil e no mundo. $1^{a}$ ed. Rio de Janeiro: Babilonia Cultura Editorial. 2017. 